\title{
The Study of Visual Functions in the Normal Eye of Patients with Unilateral Optic Neuritis.
}

\author{
Vandana Mahaur \\ Department Of Ophthalmology, SGT Medical College, Gurgaon, India
}

\begin{abstract}
:
Background: Comprehensive data on fellow eyes in unilateral optic neuritis is lacking. Aims: Evaluation of visual function of fellow eyes of patients with unilateral optic neuritis and response to treatment. Material and Methods: This was a retrospective study which included 20 patients with unilateral optic neuritis from a database of 34 patients of acute optic neuritis (bilateral or unilateral). All patients had assessment of visual acuity, contrast sensitivity, color vision, visual fields, visual evoked potentials (VEP) at presentation in affected and asymptomatic eyes. Patients were followed up at 1month, 3 months and 6 months after treatment with corticosteroids (IV Methylprednisolone followed by oral prednisone in rapid tapering doses), and then visual tests were repeated. Data was expressed as mean (95\% confidence limit) and; analyzed by Mann-Whitney $U$ test and paired t-test as appropriate. The probability level of $<0.05$ was set for statistical significance.

Result: Most of the apparently normal asymptomatic fellow eyes at baseline had abnormal visual parameters [visual fields (90\%), visual acuity (70\%), contrast sensitivity (10\%), color vision tests (10\%) and VEP (40\%)]. Mean values ( \pm standard deviation) of visual parameters were reduced [visual acuity, 0.31 ( \pm 0.280$)$ logmar values; contrast sensitivity, $1.36( \pm 0.26) \log$ units and visual fields, mean deviation $-10.03( \pm-7.39) d B$ respectively]. Most common field defect in fellow eye was peripheral scotoma, in contrast to affected eyes in which diffuse scotoma were predominant. None of the patient had dyschromatopsia. After IV Methylprednisolone, all visual parameters showed recovery which was maximum at 1 month, however only visual acuity showed a near significant trend ( $p=0.07)$.

Conclusion: Patients with 'unilateral' optic neuritis have subtle bilateral affliction, detailed evaluation of fellow eye is warranted in all cases.

Keywords- optic neuritis, unilateral, fellow eyes, Methylprednisolone
\end{abstract}

\section{Introduction}

Unilateral \& bilateral optic neuritis has been extensively studied and described by several authors in the past and recent times; however despite extensive literature search we could not find comprehensive data on fellow eyes in unilateral optic neuritis [1-4]. Only in Optic Neuritis Treatment Trial (ONTT) authors purposely tried to evaluate the visual function in fellow eyes of unilateral acute optic neuritis eyes [5]. Now there is some evidence to suggest that so called asymptomatic normal fellow eyes also demonstrate abnormal visual parameters. We have tried to study fellow eye abnormalities and response to standard treatment in some detail.

\section{Methods}

This retrospective study included patients from a data base of 34 case of acute optic neuritis (bilateral, 14 cases; unilateral, 20 cases) evaluated and followed up for 6 months after intravenous (IV) Methylprednisolone in an ophthalmology unit of a tertiary care referral hospital in Jaipur city of north India. Data of fellow eyes of 20 patients of acute unilateral optic neuritis was analyzed. Informed consent was obtained from each subject before their inclusion in the study. The study was conducted in accordance with the guidelines lay down by ICMR (2006) and Helsinki declarations (2013).

The diagnosis of optic neuritis was based on clinical symptoms and signs, fundus examination and contrast magnetic resonance imaging of optic nerve whenever feasible [6]. Patients who had symptomatic fellow eyes, previous history of optic neuritis, multiple sclerosis, previous treatment, patients with preexisting ocular abnormalities and other causes of optic neuropathies were excluded.

Each of affected and fellow eyes were tested for visual acuity (Snellen's chart), contrast sensitivity (Pelli-Robsons chart), visual field defects (Humphrey field analyzer), color vision (Ishihara pseudo-isochromatic plates) and pattern stimulated VEP (60" check size). For statistical analysis, the visual acuity score was converted to logmar units. Visual acuity was considered to be abnormal if the logmar value was greater than 0 (equivalent to 6/6). For contrast sensitivity, scores less than $1.75 \log$ units were considered abnormal. Visual fields values of mean deviation less than $-3.00 \mathrm{~dB}$ were considered abnormal. Color vision was considered to be abnormal when patient was not able to identify 1 or more Ishihara plates correctly. IV Methylprednisolone was given as per protocol (IV Methylprednisolone 1 gram infusion for 3 days, followed by oral prednisone 1 
mglkg\day for 11 days followed by rapid 3 day tapering ) and fellow eyes were followed at 1 month, 3 months and 6 months, all visual tests were then repeated.

Data was expressed as mean (95\% confidence interval). For continuous variables, a Mann-Whitney U test for unpaired data was used. Paired data was analyzed by paired t-test. The probability level of $<0.05$ was set for statistical significance. SPSS 10 (SPSS Inc, Chicago, IL) was used for statistical computations.

\section{Results}

This retrospective study enrolled 20 patients from a database of 34 acute unilateral or bilateral optic neuritis patents who were admitted under ophthalmology services of a tertiary care center in Jaipur, India and then were followed for six months. The clinical and demographic characteristics of patients enrolled in the study are shown in Table 1. The age of the patients ranged from 8 years to 67 years. The mean ( \pm standard deviation [SD]) age of the patients was $32.94( \pm 11.45)$ years. There was a predominance of male patients $(60 \%)$. Of the 20 patients, $50 \%$ had papillitis, $30 \%$ had retrobulbar neuritis and $20 \%$ patients had neuroretinitis. Etiology was unknown in majority of patients $(65 \%)$. Sinusitis was found in $30 \%$, maxillary and ethmoid sinuses were commonly involved. Left eye was affected approximately more than twice as common as right eye (14 versus 6). All the patients of unilateral optic neuritis at presentation reported loss of vision in the affected eye. Pain in and around the eye and headache was also seen in high number of patients $(80 \%)$. None of the patient had any fellow eye complaint.

When visual parameters were analyzed, visual fields were abnormal in most of the fellow eyes (90\%). Visual acuity was also unexpectedly abnormal in $70 \%$ of apparently normal asymptomatic eyes. Contrast sensitivity and color vision tests were abnormal in only $10 \%$ eyes. VEP was abnormal in $40 \%$ of unaffected eyes. Mean $( \pm \mathrm{SD})$ values of visual parameters were found to be $0.31( \pm 0.2807)$ in visual acuity (logmar values), $1.36( \pm 0.26)$ in contrast sensitivity (log units) and $-10.03( \pm 7.39)$ in visual fields (mean deviation-dB) respectively. These abnormalities were significantly milder when compared to abnormalities in affected eyes [visual acuity, $2.3708( \pm 1.001)$ logmar values; contrast sensitivity, $0.25(0.4998)$ log units; visual fields, -26.39 (10.64) mean deviation-dB; $\mathrm{p}<0.05]$ (Table 2).

Among eyes having decreased visual acuity (14 eyes), maximum (10 eyes) had mild vision loss (6/18 to $<6 / 6)$; none had severe vision loss $(<6 / 60)$. In eyes having moderate $(6 / 60$ to $<6 / 18)$ visual loss all the visual parameters were abnormal. In eyes having normal vision and mild visual loss $(6 / 18$ to $<6 / 6)$ visual field testing was able to test abnormality when contrast sensitivity and color vision tests were normal (Table 3 ).

After administration of high dose IV steroid therapy, there was near significant trend in visual acuity improvement $[00.180( \pm 0.289)$ logmar value] over one month $(P=0.077)$. Thereafter no change in mean visual acuity was noted. There was no significant change in values of contrast sensitivity and visual field testing. Abnormal patterns of field defects were also observed at baseline, during follow up and after treatment. At baseline peripheral rim scotoma was the commonest $(40 \%)$ followed by central $(20 \%)$ and multiple foci pattern $(20 \%)$ and but a 6 months no preponderance was seen. In contrast to affected eyes where diffuse pattern $(79.16 \%)$ was the commonest, none of the fellow eye had this pattern.

At six months visual acuity remained abnormal in (40\%) of all fellow eyes. At study entry only $10 \%$ of fellow eyes had normal visual fields. At 3 months, over all $60 \%$ eyes had normal visual fields but on further follow up, no additional eye improved to have a normal visual field. Two eyes which had abnormal contrast sensitivity at baseline remained abnormal, after 6 months of treatment. After 6 months visual acuity became normal in those $42.8 \%$ eyes, which had reduced vision at baseline. Overall abnormal visual fields became normal in $66.6 \%$ eyes and 2 eyes which had abnormal color vision became normal at 6 months (table 5). Visual fields testing was again able to detect abnormal fellow eye in patients with normal or near normal vision when other test (contrast sensitivity and color vision testing) failed to do so (table 6).

\section{Discussion}

This retrospective study has demonstrated that fellow eyes in cases of so called unilateral acute optic neuritis do not escape from inflammatory process; there is nothing normal about them. Most of the visual parameters are abnormal in fellow eyes and these tend to persist even after treatment with IV Methylprednisolone.

Beck et al (1984), Sanders et al (1986) have reported long back that asymptomatic visual dysfunction may be detected in the fellow eyes of a patient with acute unilateral optic neuritis [1,2]. In ONTT, abnormal visual acuity was seen in $13.8 \%$ and abnormal color vision (Ishihara plates) in $20.1 \%$ of fellow eyes. Visual field involvement was seen in maximum number of fellow eyes $(68.3 \%)$. Authors also demonstrated that when abnormalities were present in fellow eyes, these were mild [5]. In a study of 26 patients of optic neuritis (19 unilateral and 7 bilateral) in India by Sethi et al, abnormal visual fields and contrast sensitivity abnormalities were seen in more than $50 \%$ of fellow eyes of unilateral optic neuritis. Abnormal color vision and abnormal visual acuity was seen in $26.3 \%$ and $15.78 \%$ fellow eyes respectively [3]. These studies have suggested that 
fellow eyes in large number of patients of optic neuritis have subclinical involvement in all visual parameters, mostly in visual fields. We have observed similar facts, but in our study visual acuity was abnormal in more number of eyes, although severity was less. It suggested that most of our patients were not aware of the mild vision loss in fellow eyes, being more concerned with the severe vision loss in affected eyes. Testing for visual field was more rewarding in detecting the subclinical abnormality in fellow eyes as it was abnormal in the eyes having normal or near normal vision when other tests failed to do so. The pattern of field defect is different than what we see in affected eyes. As in our study, in ONTT also diffuse pattern was seen in less number of fellow eyes (18.8\% of total eyes) and among localized defects peripheral rim was commonest (22.5\%) [5].

Recently Saxena $\mathrm{R}$ et al. in a study of 99 eyes of 83 patients of optic neuritis (67 unilateral) followed for 3 years demonstrated that among fellow eyes of unilateral cases only $19.4 \%$ had decreased contrast sensitivity; there was no defect in visual field and color vision; and there was no comment on visual acuity. Since the authors have used Goldman visual fields, the subtle changes that could have been picked up on Humphrey visual fields may have been missed in their study [4].

We showed that with treatment, all the abnormal visual parameters tend to improve; however near significant trend of improvement was observed only in visual acuity. Maximum improvement in acuity was seen at one month; thereafter no further improvement was noted. Non-significant improvement in field defect though, was sustained through 6 months. Reduced visual acuity and visual field defects were the commonest abnormalities to persist at 6 months (seen in $40 \%$ fellow eyes each). Visual field testing again detected subclinical abnormality in apparently unaffected eyes (having visual acuity of 6/18 or better) at 6 months of follow up.

Sethi et al. demonstrated significant reduction in fellow eye's visual abnormalities at 6 months along with simultaneous improvement of various visual functions of affected eyes after treatment with IV Dexamethasone [3]. Saxena et al. also showed that contrast sensitivity in fellow eyes of unilateral acute optic neuritis improved after treatment with IV Dexamethasone; mean contrast sensitivity improved from $1.2 \pm 0.2$ to $1.6 \pm 0.1$ [4]. However Sethi et al. reported persistently abnormal visual parameters (visual acuity in $10.5 \%$, contrast sensitivity in $26.3 \%$, visual field defect in $21 \%$ and color vision in $10.5 \%$ of fellow eyes) at 3 months of follow up[3]. In a study by Sanders et al. also; reduced contrast sensitivity was seen in $27 \%$, visual field defects in 5\% and abnormal color vision in 14\% of unaffected eyes after 6 months of treatment of optic neuritis [2]. As evident from these studies, abnormalities in all visual parameters improve, but even after treatment they persist in fellow eyes.

At six months visual acuity became normal in $43 \%$ of fellow eyes having reduced vision at baseline. Visual field defects recovered mostly and became normal in $66.6 \%$ eyes having abnormal fields at baseline. In ONTT also maximum recovery occurred in visual fields ( $72.8 \%$ fellow eyes). Visual acuity recovered in $61.4 \%$ eyes, which had decreased vision at baseline [5]. Sethi et al. noted that at 6 months recovery occurred in $40 \%$ of fellow eyes having reduced visual acuity at base line, which is comparable to our study [3].

In detection of subclinical abnormality in fellow eye, VEP was also found to be useful; in our study $40 \%$ eyes had abnormal VEP at baseline. Sethi et al showed that pattern VEP was abnormal in $63.16 \%$ unaffected eyes; it improved with treatment, yet at 3 months follow up 31.58\% eyes had abnormal VEP [3].

Despite its merits, this study has few limitations. This was a retrospective study and the sample size was small, it probably reflected in insignificant improvement in visual parameters after treatment with steroids. The patients were followed for six months; a further follow up could have shown significant improvement in visual parameters. A prospective study with long term follow up with adequate sample size is warranted if we want to study the natural history of fellow eye abnormalities in acute unilateral optic neuritis and recurrence. Colour vision testing was done with Ishihara test, which is not as sensitive as FM 100-hue test; neither it could quantitate color vision loss. Furthermore VEP was not studied at 6 months. Hence effectiveness of these parameters in depicting improvement in fellow eyes after treatment could not be studied in detail.

Tables

Table 1: Clinical and demographic characteristics of patients with unilateral acute optic neuritis $(\mathrm{n}=20)$

\begin{tabular}{|l|c|}
\hline Parameters & No. $(\%) /$ Mean $( \pm$ SD) \\
\hline Age ( in yrs) & $32.94( \pm 11.45)$ \\
\hline Sex (male: female) & $3: 2$ \\
\hline Etiology & $13(65)$ \\
\hline Idiopathic & $06(30)$ \\
\hline Sinusitis & $01(05)$ \\
\hline Syphilis & \\
\hline Types & $10(50)$ \\
\hline Papillitis & $06(30)$ \\
\hline Retrobulbar Neuritis & $04(20)$ \\
\hline Neuroretinitis & \\
\hline Abnormal findings & \\
\hline
\end{tabular}


The Study of Visual Functions in the Normal Eye of Patients with Unilateral Optic Neuritis.

\begin{tabular}{|l|l|}
\hline Decreased Visual acuity & $14(70)$ \\
\hline Abnormal Color vision & $02(10)$ \\
\hline Abnormal Contrast sensitivity & $02(10)$ \\
\hline Visual field changes & $18(90)$ \\
\hline Visual evoked potentials & $08(40)$ \\
\hline
\end{tabular}

Data are expressed as mean \pm standard deviation (95\% confidence interval), ratio or numbers $(\%)$

Table 2: Visual parameters of affected eyes and fellow eyes in unilateral acute optic neuritis patients at baseline.

\begin{tabular}{|c|c|c|c|c|}
\hline & \multicolumn{2}{|c|}{ Affected eyes $(n=20)$} & \multicolumn{2}{|c|}{ Fellow eyes $(\mathrm{n}=20)$} \\
\hline Visual parameters & Mean \pm SD & $\begin{array}{c}\text { Abnormal parameters } \\
(\%)\end{array}$ & Mean \pm SD & Abnormal parameters (\%) \\
\hline $\begin{array}{l}\text { Visual acuity (logmar } \\
\text { units) }\end{array}$ & $\begin{array}{r}02.370 \\
\pm 01.001\end{array}$ & $20(100)$ & $\begin{array}{c}00.310 \\
\pm 00.280\end{array}$ & $14(70)$ \\
\hline $\begin{array}{l}\text { Contrast sensitivity } \\
\text { (log units) }\end{array}$ & $\begin{array}{c}00.250 \\
\pm 00.499\end{array}$ & $18(90)$ & $\begin{array}{c}01.365 \\
\pm 00.259\end{array}$ & $02(10)$ \\
\hline Visual field $(\mathrm{dB})$ & $\begin{array}{c}26.390 \\
\pm 10.640\end{array}$ & $20(100)$ & $\begin{array}{c}10.027 \\
\pm 07.396\end{array}$ & $18(90)$ \\
\hline Color vision & - & $18(90)$ & - & $02(10)$ \\
\hline
\end{tabular}

Data are expressed as mean \pm standard deviation (95\% confidence interval), ratio or numbers $(\%)$

Table 3: Abnormal results on contrast sensitivity, visual fields and color vision testing by visual acuity level in fellow eyes at base line $(n=20)$

\begin{tabular}{|l|c|c|c|c|}
\hline Visual acuity & $\begin{array}{c}\text { No. of fellow eyes } \\
(\%)\end{array}$ & Contrast Sensitivity (\%) & Visual fields (\%) & $\begin{array}{c}\text { Color vision } \\
\text { Testing }(\%)\end{array}$ \\
\hline PL - & $00(00)$ & $00(00)$ & $00(00)$ & $00(00)$ \\
\hline PL + & $00(00)$ & $00(00)$ & $00(00)$ & $00(00)$ \\
\hline HM to $<6 / 60$ & $00(00)$ & $00(00)$ & $00(00)$ & $00(00)$ \\
\hline $6 / 60$ to $<6 / 18$ & $04(20)$ & $02(10)$ & $02(10)$ & $02(10)$ \\
\hline $6 / 18$ to $<6 / 6$ & $10(50)$ & $00(00)$ & $08(40)$ & $00(00)$ \\
\hline $6 / 6$ or better & $06(30)$ & $00(00)$ & $08(40)$ & $00(00)$ \\
\hline Total & $20(100)$ & $02(10)$ & $18(90)$ & $02(10)$ \\
\hline
\end{tabular}

Data are expressed in numbers (\%). Visual acuity checked on Snellen's chart. PL-, perception of light absent; PL+, perception of light present; HM, hand movement.

Table 4: Trends in visual parameters before and after treatment of fellow eyes $(n=20)$

\begin{tabular}{|c|c|c|c|c|c|c|}
\hline Visual parameters & BASELINE & $1^{\text {st }}$ week & $1^{\mathrm{ST}}$ Month & $3^{\text {rd }}$ Month & $6^{\text {th }}$ Month & $\mathrm{p}$ value \\
\hline $\begin{array}{l}\text { Visual acuity in logmar units } \\
( \pm \text { SD })\end{array}$ & $\begin{array}{c}00.310 \\
(0.2807)\end{array}$ & $\begin{array}{l}00.220 \\
(0.274)\end{array}$ & $\begin{array}{l}00.180 \\
(0.289)\end{array}$ & $\begin{array}{l}00.180 \\
(0.289)\end{array}$ & $\begin{array}{l}00.180 \\
(0.289)\end{array}$ & 0.077 \\
\hline $\begin{array}{l}\text { Contrast sensitivity } \\
\text { in } \log \text { units }( \pm S D)\end{array}$ & $\begin{array}{l}01.365 \\
(0.259)\end{array}$ & $\begin{array}{l}01.365 \\
(0.259)\end{array}$ & $\begin{array}{l}01.425 \\
(0.276)\end{array}$ & $\begin{array}{l}01.425 \\
(0.276)\end{array}$ & $\begin{array}{l}01.425 \\
(0.276)\end{array}$ & 0.104 \\
\hline Visual field in $\mathrm{dB}( \pm \mathrm{SD})$ & $\begin{array}{c}-10.030 \\
(7.396)\end{array}$ & - & $\begin{array}{r}-07.939 \\
(6.186)\end{array}$ & $\begin{array}{c}-06.496 \\
(6.614)\end{array}$ & $\begin{array}{c}-06.184 \\
(6.709)\end{array}$ & 0.101 \\
\hline
\end{tabular}

Data are expressed as mean (standard deviation, 95\% confidence limit). Standard deviation, SD; Mean deviation, $\mathrm{dB}$

Table 5: Changes in visual parameters in fellow eyes from baseline to six months $(\mathrm{n}=20)$

\begin{tabular}{|l|c|c|c|c|}
\hline & Visual acuity & Contrast sensitivity & Visual fields & Color vision \\
\hline $\begin{array}{l}\text { No of abnormal eyes at baseline } \\
(\%)\end{array}$ & $14(70)$ & $02(10)$ & $18(90)$ & $02(10)$ \\
\hline $\begin{array}{l}\text { Eyes becoming normal } \\
\text { at } 6 \text { month (\%) }\end{array}$ & $06(42.8)$ & $00(00)$ & $12(66.6)$ & $02(100)$ \\
\hline
\end{tabular}

Data are expressed in numbers $(\%)$.

Table 6: Abnormal results of contrast sensitivity, visual fields and color vision testing, by visual acuity level in fellow eyes at six months $(\mathrm{n}=20)$

\begin{tabular}{|l|c|c|c|c|}
\hline Visual acuity & No. of affected eyes $(\%)$ & Contrast Sensitivity (\%) & $\begin{array}{c}\text { Visual fields, } \\
(\%)\end{array}$ & $\begin{array}{c}\text { Color vision } \\
\text { Testing }(\%)\end{array}$ \\
\hline PL - & $00(00)$ & $00(00)$ & $00(00)$ & $00(00)$ \\
\hline PL + & $00(00)$ & $00(00)$ & $00(00)$ & $00(00)$ \\
\hline HM to $<6 / 60$ & $00(00)$ & $00(00)$ & $00(00)$ & $00(00)$ \\
\hline $6 / 60$ to $<6 / 18$ & $04(20)$ & $02(10)$ & $04(20)$ & $00(00)$ \\
\hline $6 / 18$ to $<6 / 6$ & $04(20)$ & $00(00)$ & $02(10)$ & $00(00)$ \\
\hline $6 / 6$ or better & $12(60)$ & $00(00)$ & $02(10)$ & $00(00)$ \\
\hline
\end{tabular}


The Study of Visual Functions in the Normal Eye of Patients with Unilateral Optic Neuritis.

\begin{tabular}{|l|c|c|c|c|}
\hline Total & 20 & $01(10)$ & $04(40)$ & $00(00)$ \\
\hline
\end{tabular}

Data are expressed in numbers (\%). Visual acuity checked on Snellen's chart. PL-, perception of light absent; $\mathrm{PL}+$, perception of light present; HM, hand movement.

\section{Conclusion}

Mild visual loss was seen in most of the fellow eyes. Visual field testing detected subclinical optic nerve dysfunction in most of so called normal fellow eyes even when other parameters were normal. Good recovery was seen in fellow eyes after treatment; some abnormalities persisted but were mild. Visual field testing again detected residual optic nerve dysfunction in apparently normal fellow eyes after completion of follow up. Therefore detailed and careful ophthalmologic examination and various visual function tests are indispensable and can detect evidence of optic nerve dysfunction even in asymptomatic eyes as we have seen above.

\section{References}

[1]. Beck RW, Ruchman MC, Savino PJ, Schatz NJ. Contrast sensitivity measurements in acute and resolved optic neuritis. BJO 1984; 68:756-59.

[2]. Sanders EA, Volkers AC, Van Der Poel JC, Van Lith GH. Estimation of visual function after optic neuritis: a comparison of clinical tests. BJO 1986, 70:918-24.

[3]. Sethi HS, Menon V, Sharma P, Khokhar S, Tandon R. Visual outcome after intravenous Dexamethasone therapy for idiopathic optic neuritis in an Indian population: A clinical case series. Indian journal of ophthalmology 2006; 54: 177-83.

[4]. Saxena R, Phuljhele S, Menon V, Gadaginamath S, Sinha A, Sharma P. Clinical profile and short-term outcomes of optic neuritis patients in India. Indian journal of ophthalmology 2014; 62: 265-67.

[5]. Beck RW, Kupersmith MJ, Cleary PA, Katz B. The Optic Neuritis Study Group. Fellow eye abnormalities in acute unilateral ON. Experience of the ONTT. Ophthalmol 1993; 100:691-8.

[6]. Optic Neuritis Study Group. The clinical profile of optic neuritis: experience of the Optic Neuritis Treatment Trial. Archives of Ophthalmology 1991; 109: 1673-8. 